\title{
Let Optimization be Your Guide for a Magical Family Trip in Disneyland Paris
}

\author{
Amalia Chatzigeorgiou, Konstantina Kyriakou, and Georgia Lazaridou \\ Department of Mathematics and Statistics, University of Cyprus, Cyprus \\ \{chatzigeorgiou.amalia, kyriakou.m.konstantina, lazaridou.georgia\}@ucy.ac.cy
}

Advisor: Angelos Georghiou

Department of Business and Public Administration, University of Cyprus, Cyprus

georghiou.angelos@ucy.ac.cy

\begin{abstract}
Disneyland is a magical place for young and old alike. Yet the size of the park, the age restrictions of the attractions, the preferences amongst different age groups and the time a family could spend in the park, makes it difficult to decide which attractions to visit. By collecting data from the Disneyland Paris website and other reliable sources which include ratings of the attractions for each age group, we formulate an Orienteering Problem that aims to find the route achieving the maximum total rating. Our case study tries to answer two questions: (i) how should each family member individually navigate the park maximizing his/hers total rating, and (ii) how should a family as a single group navigate the park such that all family members achieve their goals. Our results show that if the family stay as a single group, the loss in total rating is negligible compared to each family member navigating the park individually.
\end{abstract}

Keywords. Mixed-Integer Optimization, Orienteering Problem, Modeling, Disneyland Paris

\section{Introduction}

Founded in 1992, Disneyland Paris is one of the most visited attractions in Europe, attracting more than 15 million visitors per year (1). Disneyland Paris, separated in two parks: the Disneyland Park 
and the Walt Disney Studio Park, is a children's favorite, and is a must see location for families visiting Paris. The park claims to have attractions for all ages so as the whole family can have an unforgettable experience. With 46 attractions it can accommodate all ages and tastes. Ideally to fully experience the park, one will need to spend several days. This is usually not possible for the majority of visitors that usually have time and budget restrictions, spending one or two days in the park (9). So families need to be "strategic" and optimize how they should visit attractions, maximizing their experience!

As with all theme parks, some attractions are more popular than others. There are many guides trying to suggest the most noteworthy attractions $(3 ; 15)$. A measure of popularity is the rating reported by visitors in a trusted touring plan website (15). The website provides ratings for each attraction based on different age groups. The age groups are: Preschoolers, Kids, Tweens, Teenagers and Adults, and the rating ranges from 0 to 5 , with 5 being the highest. With millions of votes, the rating system is a robust measure of the popularity of each attraction. Some attractions in Disneyland Paris have restrictions such as age and height while others are simply unsuitable for young children as they are too scary (5). Despite these restrictions, (15) provides ratings for all the attractions as shown in Table 7 of Appendix A. Figure 1 indicates the geographic location of the attractions based on age restrictions, from which we can conclude that attractions are not grouped based on age restrictions but rather scattered throughout the park. Figure 2 indicates the rating of the attractions based on the different age groups. A naive approach is to visit attractions according to the highest rating. However, this will result in traversing through the park unnecessarily, losing precious time and not experiencing the park to the fullest. Motivated by our plan to visit Disneyland in the coming years, our aim is to explore how a family should plan their visit to the park in order to achieve a magical experience.

In this paper, we apply optimization techniques to help a family plan a trip to Disneyland Paris. Our aim is two fold. First, we 4 study how each family member should navigate the park individually maximizing his/hers experience, and second we study how a family consisting of multiple age groups should navigate the park such that all family members can have a good time. For each age group, we use the rating of each attraction as a measure of how much fun they will have. To measure the experience of the family as they navigate the park together, for each attraction we use the average rating of the age groups that form the family. In the first study we 


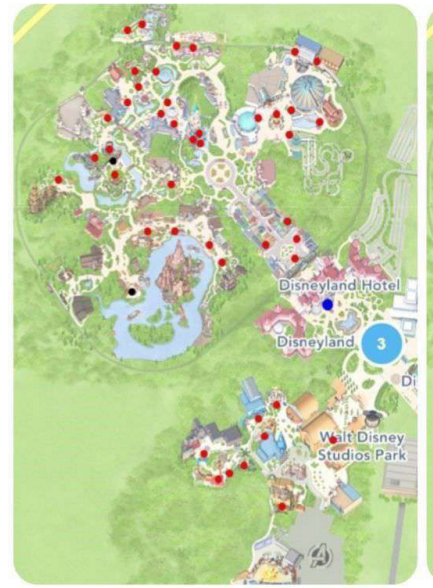

Adults Teenagers

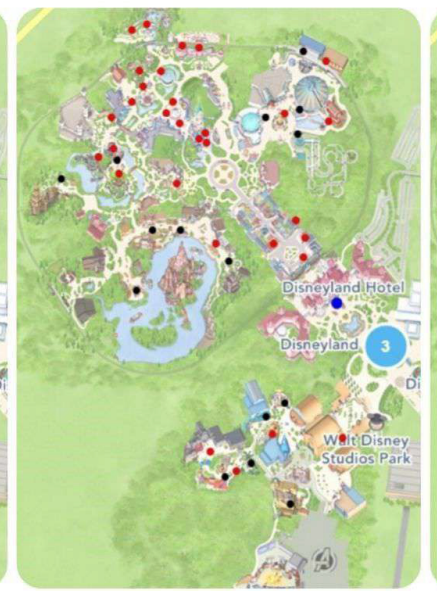

Preschoolers

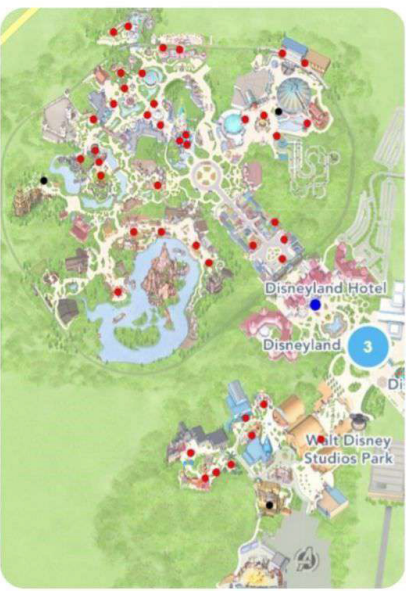

Kids

Figure 1. Age restrictions of the attractions in Disneyland Paris. Red dots represent available attractions while black dots represent attractions that the given age group cannot visit. The blue dot indicates the entrance to the park. The age group of Tweens is not included as they have no restrictions at all.

see the ultimate rating each age group can achieve individually, while in the second experiment we see the compromise that each age group experiences as the family visits the attractions as a single group. In both cases, we seek to find routes that maximize the total rating of the attractions visited while satisfying time availability and age group restrictions. Generally, our study focuses on the variety of age groups within a family which we systematically study by formulating several optimization problems in order to understand how the change of other factors like available time and rate of attraction acts on each age group. The difficulty of these problems is the diversity of the park's attractions that are not only aimed at different age groups but also have different ratings for each group. So, family members need to compromise in order for the family to achieve the highest total average rate while satisfying time restrictions and personal preferences.

To find the best routes for the family we formulate the problem as an Orienteering Problem (7). The Orienteering Problem is a routing problem in which the goal is to determine a subset of nodes to visit and in which order, so that the collected reward is maximized and a given time budged is not exceeded. The problem results in a mixed-integer optimization problem. The Orienteering Problem is well suited for the application in hand as the optimal route visits only a subset of the attractions and tries to maximize the sum of rating from the visited attractions while satisfying the time and age 

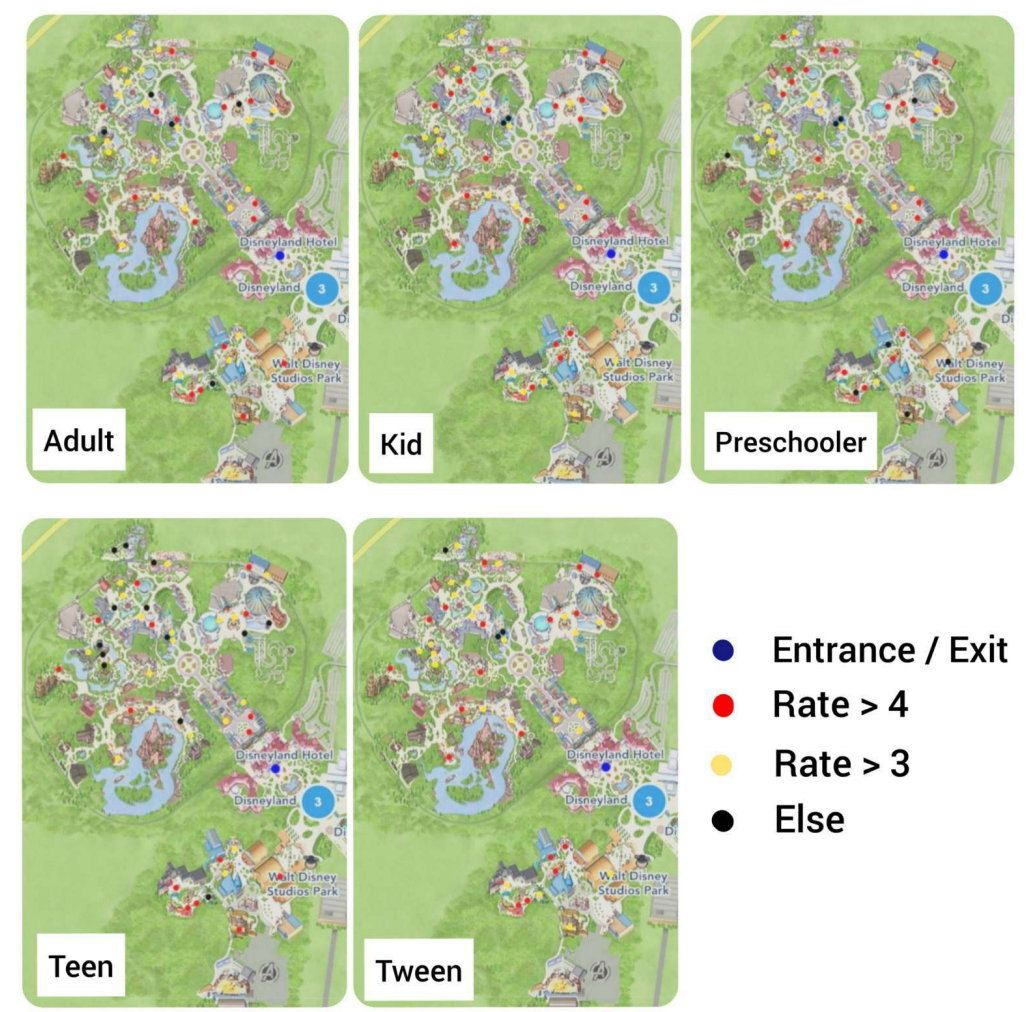

- Entrance / Exit

- Rate $>4$

Rate $>3$

- Else

Figure 2. Rating of each attraction for each age group on the Disneyland map.

restrictions. The Orienteering Problem has been successfully used in many applications. In (7) the authors use a variant of the Orienteering Problem formulation for home fuel delivery. The aim is to deliver fuel to as many customers as possible while maintaining inventory fuel levels and satisfying time budget constraints. Also, in (18) the Orienteering Problem is used for scheduling submarine and unmanned aircraft where the aim is to maximize surveillance coverage subject to fuel and time constraints. In addition, (6) uses the Orienteering Problem to study a route-planning problem such that tourists can plan their visit in multiple points of interest during their vacation. Moreover, the author of (16) describes the case of a traveller with not enough time to visit all possible cities. He knows the expected number of sales in each city and wants to maximize total sales, while keeping the total travel time limited to a day (or week). One could alternatively formulate the problem as the Prize Collecting Traveling Salesman Problem like (2) which is similar in spirit to the Orienteering Problem. The main difference is that the salesman needs to pay "transportation cost" for every pair of nodes he visits, while he has to pay a "penalty" for every node which is not visited. In addition, rather than maximizing the overall rewards collected, the Prize Collecting 
Traveling Salesman Problem imposes a constraint on the minimum number of rewards that need to be collected while minimizing the overall cost. Another application of this is used by the authors in (14) in a single-ring design problem. In contrast, the Orienteering Problem maximizes rewards subject to a budget constraint on the overall time allowed. The two formulations could potentially be used interchangeably, however, we believe the Orienteering formulation is better suited for our case. More applications of the Orienteering Problem are surveyed in $(17 ; 8)$.

An important question for everyone visiting Disneyland is how much time they should spend in the park. Disneyland Paris offers a variety of tickets for visiting the park. Briefly, the first option is to buy a 1-Day ticket that either has access to one part of park or all the park. The second option is to buy a Multi-Day ticket to make the magic last longer and enjoy even more adventures in both parks, and the last option is annual passes. In summary, there are three types of tickets: the Mini Ticket, the Magic ticket and the Super Magic ticket which refer to the validity periods as shown in Disneyland's official website calendar (4). For the purpose of this study, we consider that the visitors buy a Super Magic 1-Day Ticket which gives them access to both parks and there is no need for extra cost during their trip.

The contributions of this paper are:

- We formulated the problem as an orienteering problem. We provide formulations for each age group to model the restrictions and requirements according to the attributes of each attraction. The formulation of the constraints is modular and can easily be extended to model other attraction parks.

- We examine how each age group will optimally navigate the park. We study the trade-off between the hours spent in the park and the experience achieved, measured as the number of attractions visited and the total rate collected. This analysis compares the behaviour between the age groups and provides insights on how much time a visitor should spend in order to achieve given levels of satisfaction.

- We examine how a family formed by members of different age groups should navigate the park. As different age groups would have different priorities in the attractions they might want to visit, we study how a family should split its time, first navigating the park as a single group and then each age group visiting the attractions individually. Our results provide 
insights on how the available time, and the split of available time impacts the rating for each age group.

The paper is structured as follows. In Section 2, we examine the data set collected for Disneyland Paris and study what attributes of the attractions have an impact on the different age groups. In Section 3, we formulate the orienteering problem and discuss restrictions of the different age groups. In Section 4 we present the findings of our case study about a family trip and discuss the implications of the time and age restrictions. Finally, our conclusions and remarks can be found in Section 5 .

\section{Data Description}

In this study we use data for Disneyland Paris, collected from the official web page of Disneyland Paris (5). In cases of missing data for some of the attractions, we substituted data from Disneyland Park in California which has the same attractions (15). All data used for this study can be found in Appendix A in Tables 7-10.

Disneyland Paris' provision of different facilities to its visitors gives us the opportunity to classify the attractions by their characteristics and services. Disneyland has one entrance which is used as an exit too, forty-six attractions and it is divided into two major areas: Disneyland Park and Walt Disney Studios Park. Particularly, Disneyland Park is separated into five smaller areas: Discoveryland, Fantasyland, Adventureland, Frontierland and Main Street USA while Walt Disney

Studios Park is separated into the following three sub-areas: Production Courtyard, ToonStudio and Front Lot.

Each of Disneyland's activities has the following characteristics: location, wait time in the queue based on a day with moderate crowds and duration. Some attractions have extra restrictions, such as age and height limit. The five age groups are: Preschoolers (ages 3-5), Kids (ages 6-10), Tweens (ages 10-13), Teenagers (ages 14-18) and Adults (ages 18+). Each age group rates the attractions differently. The ratings of the attractions for each age group is summarized in Table 1. It is clear that Kids have lots of high rated attractions while Teenagers quite a few low rated attractions compared to the other age groups. We can also notice that despite the age restrictions, Preschoolers have a large number of high rated attractions. This leads us to conclude that the target audience of Disneyland might be a younger audience. Table 2 summarizes the number of attractions each 
age group can visit as well as the rate each group can achieve by visiting all attractions without age group restriction. We see that Preschoolers have the most restrictions, while for the rest of the age groups the restrictions are few, with Tweens having no restrictions at all. Finally, Table 3 presents the correlation of the rating between different age groups. We observe that Tweens and Kids as well as Teenagers and Adults have a high positive correlation. The correlation between Tweens and Adults and the correlation between Kids and Adults is almost identical and it indicates a moderate positive relationship between them.

Table 1. Number of Attractions in each rate range according to age groups.

\begin{tabular}{c|ccccc}
$\begin{array}{c}\text { Range of } \\
\text { Attractions' Rate }\end{array}$ & Preschooler & Kid & Tween & Teenager & Adult \\
\hline $0<$ Rate $\leq 1$ & 0 & 0 & 0 & 2 & 0 \\
$1<$ Rate $\leq 2$ & 0 & 0 & 0 & 2 & 1 \\
$2<$ Rate $\leq 3$ & 3 & 2 & 3 & 8 & 4 \\
$3<$ Rate $\leq 4$ & 13 & 21 & 25 & 17 & 21 \\
$4<$ Rate $\leq 5$ & 15 & 20 & 18 & 15 & 18 \\
\hline
\end{tabular}

Table 2. The number of available and restricted attractions for each age group and the maximum possible rate achieved if all the available attractions are visited.

\begin{tabular}{r|ccccc} 
& Preschoolers & Kids & Tweens & Teenagers & Adults \\
\hline Available Attractions & 31 & 43 & 46 & 44 & 44 \\
Restricted Attractions & 15 & 3 & 0 & 2 & 2 \\
Maximum Possible Rate & 123.6 & 173.5 & 181.9 & 158 & 168.85 \\
\hline
\end{tabular}

Table 3. Correlation Coefficients for the ratings of different age groups

\begin{tabular}{r|ccccc} 
Age Groups & Preschoolers & Kids & Tweens & Teenagers & Adults \\
\hline Preschoolers & 1.0000 & 0.3309 & -0.0431 & -0.2995 & -0.1699 \\
Kids & 0.3309 & 1.0000 & 0.8226 & 0.4373 & 0.4994 \\
Tweens & -0.0431 & 0.8226 & 1.0000 & 0.4717 & 0.5263 \\
Teenagers & -0.2995 & 0.4373 & 0.4717 & 1.0000 & 0.7028 \\
Adults & -0.1699 & 0.4994 & 0.5263 & 0.7028 & 1.0000 \\
\hline
\end{tabular}

Besides the above attributes, each activity has the following features: "Family Adventure", "Fun for Little ones", "Guest may get Splashed", "Not to be Missed" and "May Frighten Younger visitors" as shown in the Table 9 in Appendix A. Finally, each attraction provides some services such as: "Single Rider Service", "Fastpass", "PhotoPassTM", "Meet Disney Characters". Especially, "Fastpass" indicates that the visitor can cut down queue times on this attraction and with Disney "PhotoPassTM" the visitor can acquire a digital portfolio of all his souvenir photos taken during his visit to Disneyland Paris, whether on the Attractions, or by Disney PhotoPass Photographers. The different services are summarized in Table 8 of the Appendix A. Along with the tables, Figure 
3 illustrates a plot of the different features and services provided by the attractions. Generally, some attractions have a combination of these features. This is an advantage for a family visiting the park as each family member can combine his/her choices in order to satisfy all his/her individual preferences.

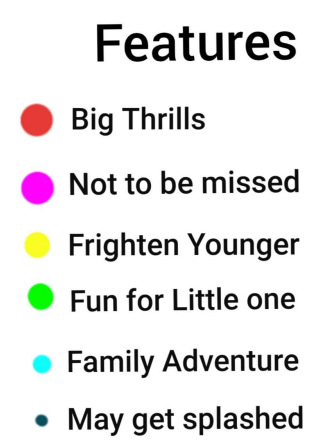

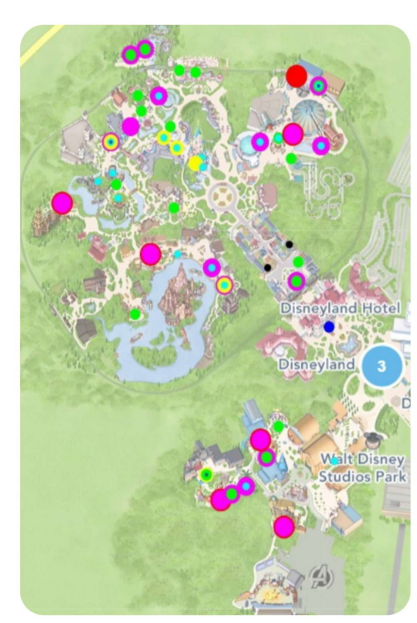

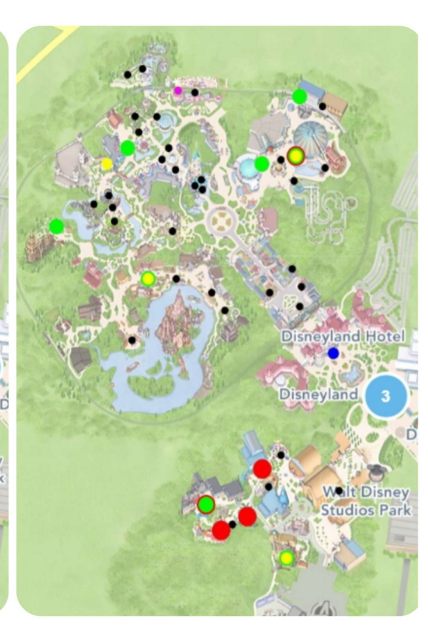

\section{Services}

Single Rider

Fast Pass

Photo Pass

- Meet Disney Characters

Figure 3. These maps represent the services and features of attractions in Disneyland's map where the black bullets indicate the position of the attraction and the blue electric bullet is the entrance/exit.

To better understand which attributes have an impact on the rating of each age group, we performed regression analysis. Using the rating of each age group, shown in Table 7 in Appendix A, as the dependent variable and the variables "Height", "Duration", "Wait time", "Suitable for Preschoolers", "Suitable for Kids", "Suitable for Teenagers and Adults", "Family Adventure", "Fun for little Ones", "Guest May Get Splashed", "Not to be Missed", "Big Thrills", "May Frighten Younger Guests", "Single Rider Service", "Fastpass", "PhotoPassTM" and "Meet Disney Characters" as the independent variables, we fit a linear regression model. In order to get more accurate models, we selected the best model using the forward step algorithm based on the P-values. The algorithm is provided by the ols_step_forward_p function in $\mathrm{R}(10)$. The models are presented in Table 4. As one would expect the rating of each age group is affected by the attributes of the attractions. For example, we see that "Fun for little ones" has a positive impact on the ratings of preschoolers, while "Big thrills" has a negative impact. In contrast, "Big thrills" has a positive impact on the rating of teenagers and adults. It is also interesting to see that $R^{2}=0.7438$ for preschoolers implying that their rating can be largely explained by the given attributes, while for the rest of the age groups $R^{2} \approx 0.4$ indicating that other factors can affect their rating. 
Table 4. Linear Regression Analysis of Age Groups' rating

\begin{tabular}{|c|c|c|c|c|c|}
\hline Age Group & Name of Variable & $\begin{array}{l}\text { Estimate } \\
\text { Value }\end{array}$ & $\begin{array}{l}\text { Std. } \\
\text { Error }\end{array}$ & P-Value & \\
\hline Preschoolers & Intercept & 3.3825 & 0.1965 & $<2 \mathrm{e}-16$ & $* * *$ \\
\hline$R^{2}=0.7438$ & Big Thrills & -1.4618 & 0.2981 & $1.79 \mathrm{e}-05$ & $* * *$ \\
\hline $\mathrm{F}$ significance $=1.701 e-09$ & Fastpass & 1.1554 & 0.2398 & $2.34 \mathrm{e}-05$ & $* * *$ \\
\hline \multirow[t]{5}{*}{ Adjusted $R^{2}=0.6966$} & Fun for little ones & 0.8365 & 0.2097 & 0.000291 & $* * *$ \\
\hline & Kids restrictions & -1.2136 & 0.3744 & 0.002474 & $* *$ \\
\hline & PhotoPassTM & 0.7063 & 0.3057 & 0.26387 & $*$ \\
\hline & Guest may get splashed & -0.6648 & 0.3060 & 0.036111 & $*$ \\
\hline & Family Adventure & 0.3561 & 0.2089 & 0.096475 & . \\
\hline Kids & Intercept & 3.6698 & 0.1180 & $<2 \mathrm{e}-16$ & $* * *$ \\
\hline$R^{2}=0.3511$ & Wait time & 0.0049 & 0.0037 & 0.1954 & \\
\hline $\mathrm{F}$ significance $=0.01467$ & Fastpass & 0.4203 & 0.2164 & 0.0596 & . \\
\hline \multirow[t]{5}{*}{ Adjusted $R^{2}=0.2316$} & Fun for little ones & 0.2215 & 0.1322 & 0.1021 & \\
\hline & Not to be missed & 0.2736 & 0.1404 & 0.0588 & . \\
\hline & Single rider service & -0.3605 & 0.2178 & 0.1062 & \\
\hline & Kids restrictions & -0.4472 & 0.3159 & 0.1650 & \\
\hline & Preschoolers restrictions & 0.1957 & 0.1563 & 0.2183 & \\
\hline Tweens & Intercept & 3.5632 & 0.1164 & $<2 \mathrm{e}-16$ & $* * *$ \\
\hline$R^{2}=0.3698$ & Not to be missed & 0.2815 & 0.1640 & 0.0939 & . \\
\hline $\mathrm{F}$ significance $=0.001824$ & Fastpass & 0.2658 & 0.2287 & 0.2520 & \\
\hline \multirow[t]{3}{*}{ Adjusted $R^{2}=0.291$} & Preschoolers Restrictions & 0.3144 & 0.1814 & 0.0907 & . \\
\hline & Guest may get splashed & 0.4038 & 0.3145 & 0.2066 & \\
\hline & Wait time & 0.0048 & 0.0044 & 0.2775 & \\
\hline Teenagers & Intercept & 3.3000 & 0.1282 & $<2 \mathrm{e}-16$ & $* * *$ \\
\hline$R^{2}=0.3539$ & Big Thrills & 1.4571 & 0.3178 & $3.88 \mathrm{e}-05$ & $* * *$ \\
\hline $\begin{array}{l}\text { F significance }=8.351 e-05 \\
\text { Adjusted } R^{2}=0.3238\end{array}$ & Guest may get splashed & 0.9667 & 0.4623 & 0.0425 & $*$ \\
\hline Adults & Intercept & 3.4858 & 0.1115 & $<2 \mathrm{e}-16$ & $* * *$ \\
\hline$R^{2}=0.5269$ & Not to be missed & 0.5340 & 0.1688 & 0.00293 & $* *$ \\
\hline $\mathrm{F}$ significance $=5.433 e-05$ & Big Thrills & 1.8300 & 0.5387 & 0.00152 & $* *$ \\
\hline \multirow[t]{2}{*}{ Adjusted $R^{2}=0.3929$} & Height restrictions & -1.1053 & 0.4545 & 0.01948 & $*$ \\
\hline & May frighten younger guests & 0.4278 & 0.2349 & 0.07588 & . \\
\hline
\end{tabular}

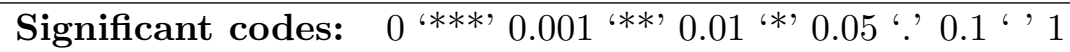

Sample size for all age groups $=46$

\section{Problem Formulation}

In this section we formulate the problem as an Orienteering Problem to find the best route through the park. We adopt the formulation in (8) which uses Miller-Tucker-Zemlin formulation for the subtour elimination (13). We denote by $N$ the number of attractions in the park. By convention 
we have that attractions 1 and $N+2$ indicate the entrance and exit of the park, respectively. Let $x_{i, j}, i, j=1, \ldots, N+2$, be binary variables such that

$$
x_{i, j}:=\left\{\begin{array}{ll}
1 & \text { if visitor goes from attraction } i \text { to attraction } j \\
0 & \text { otherwise }
\end{array}\right\} .
$$

Let $u_{i}, i=2, \ldots, N+2$, be integer variables. The values of the $u_{i}$, in ascending order, represent the order of attractions visited. For example, consider that a visitor will visit ten attractions. If we put the values of the variables $u_{2}, \ldots, u_{12}$ in a list and sort them in ascending order, we can say that the attraction $i$ is visited first if $u_{i}$ has the smallest value, attraction $j$ is visited second if $u_{j}$ has the second smallest value, etc.

Our orienteering problem uses the rating to decide which attractions to visit and aims to maximize the sum of the visited attractions' rate. We denote by $r_{i}$ the rating of attraction $i$. Note that $r_{1}=r_{N+2}=0$ since node 1 and $N+2$ are the entrance and exit of the park, respectively. Hence, we aim to maximize the objective function

$$
\sum_{i=2}^{N+1} \sum_{j=2}^{N+2} r_{i} x_{i, j}
$$

The following constraints enforce the routing problem.

$$
\begin{gathered}
\sum_{j=2}^{N+2} x_{1, j}=\sum_{i=1}^{N+1} x_{i, N+2}=1, \\
x_{i, i}=0, \quad \forall i=1, \ldots, N+2,
\end{gathered}
$$

and

$$
\sum_{i=1}^{N+1} x_{i, k}=\sum_{j=2}^{N+2} x_{k, j} \leq 1, \quad \forall k=2, \ldots, N+1 .
$$

Constraint (3.3) ensures that the visitor should start his/her path from the entrance and finish at the exit, while constraint (3.4) ensures that the visitor is not allowed to stay at the same attraction. Constraint (3.5) ensures that each attraction is visited at most once. 
The following constraint ensures that the visitor not exceed the available time.

$$
\sum_{i=1}^{N+1} \sum_{j=2}^{N+2} t_{i, j} x_{i, j} \leq \operatorname{Tmax} .
$$

Here Tmax denotes the time in minutes available to the visitor. The constants $t_{i, j}$ denote the sum of minutes needed for the visitor to walk from attraction $i$ to attraction $j$ plus the wait time and duration of attraction $i$. For the calculation of the walking minutes from attraction $i$ to $j$, we used the walking time information given in Google Maps.

As described previously, the integer decision variables $u_{i}$ are responsible for the path that the visitor will follow, taking values in $[2, N+2]$, i.e.,

$$
2 \leq u_{i} \leq N+2, \forall i=2, \ldots, N+2
$$

with the following constraint ensuring that the path will not contain sub-tours

$$
x_{i, j}(N+1)+u_{i}-u_{j} \leq N, \forall i=2, \ldots, N+1, \forall j=2, \ldots, N+2 .
$$

Constraint (3.8) usually referred to as the Miller-Tucker-Zemlin constraint.

Finally, we look at the constraints about age restrictions. The visitor cannot visit certain attractions, see Table 10 of the Appendix A. For each age group the same method is followed: For each attraction $i$ that cannot be visited by the specific age group, then $x_{i, j}=0$, for all $j=2, \ldots, N+2$ and $x_{i, j}=0$, for all $i=1, \ldots, N+1$. The overall problem can be cast as the following mixed-integer optimization problem.

$$
\begin{array}{ll}
\text { maximize } & \sum_{i=2}^{N+1} \sum_{j=2}^{N+2} r_{i} x_{i, j} \\
\text { subject to } & (3.3)-(3.8), \\
& x_{i, j} \in\{0,1\} \text { and } u_{i} \in \mathbb{Z}, \text { and } \\
& \text { age group restrictions. }
\end{array}
$$




\section{Case Studies through Numerical Experiments}

In the following, we perform numerical studies to understand how different age groups navigate the park, and how a family should approach a trip to Disneyland Paris. All optimization problems were solved in Matlab using Gurobi 8.0.0 optimizer see (www.gurobi.com) through the Yalmip interface (12). The source code and data used can be found in (11). We use a stopping criterion of 2 hours which was only needed for a small number of instances. For these instances, the gap between the upper and lower bounds was less than $1 \%$. Hence, in the following we don't report solution times as they are not insightful.

\subsection{Age Groups Experiment}

In this section we solve the problem with only age restrictions in order to understand how the total rate and total visited attractions is affected by the available time for each age group. For this numerical experiment, we first consider that the visitor has 600 minutes (10 hours) available in Disneyland. For each age group, we solved problem (3.9) by imposing the appropriate age group restrictions. The optimal solution for each of these problems as well as its optimal value can be shown in the Disneyland's maps in Figure 4. We observe that Kids and Tweens can achieve higher total rating and visit more attractions than Preschoolers, Teenagers and Adults. This is because Disneyland has more attractions that interest young visitors. Preschoolers and Teenagers' total rating is lower as Preschoolers have stricter restrictions and Teenagers have many low rated attractions. Adults' optimal rating is similar to Kids and Tweens since their ratings are moderatily correlated and don't have significant age restrictions.

We next try to understand how time restrictions affect the optimal solution. To this end, for each age group, we solved the problem for different values of Tmax $\in\{0,60,120,180, \ldots, 600\}$. In each run, we record the optimal value of the problem and the number of attractions visited. Our aim is to understand the relation between the total rate achieved and the time available. The results are depicted in Figure 5. We can see the diminishing total rating achieved as the available time increases. The age groups Kids and Tweens achieve larger total ratings, while Preschoolers achieve lower values as it is the age group with the most restrictions. This is evident from Table 2.

It is of course desirable to spend as much time as possible in Disneyland, however, this might 

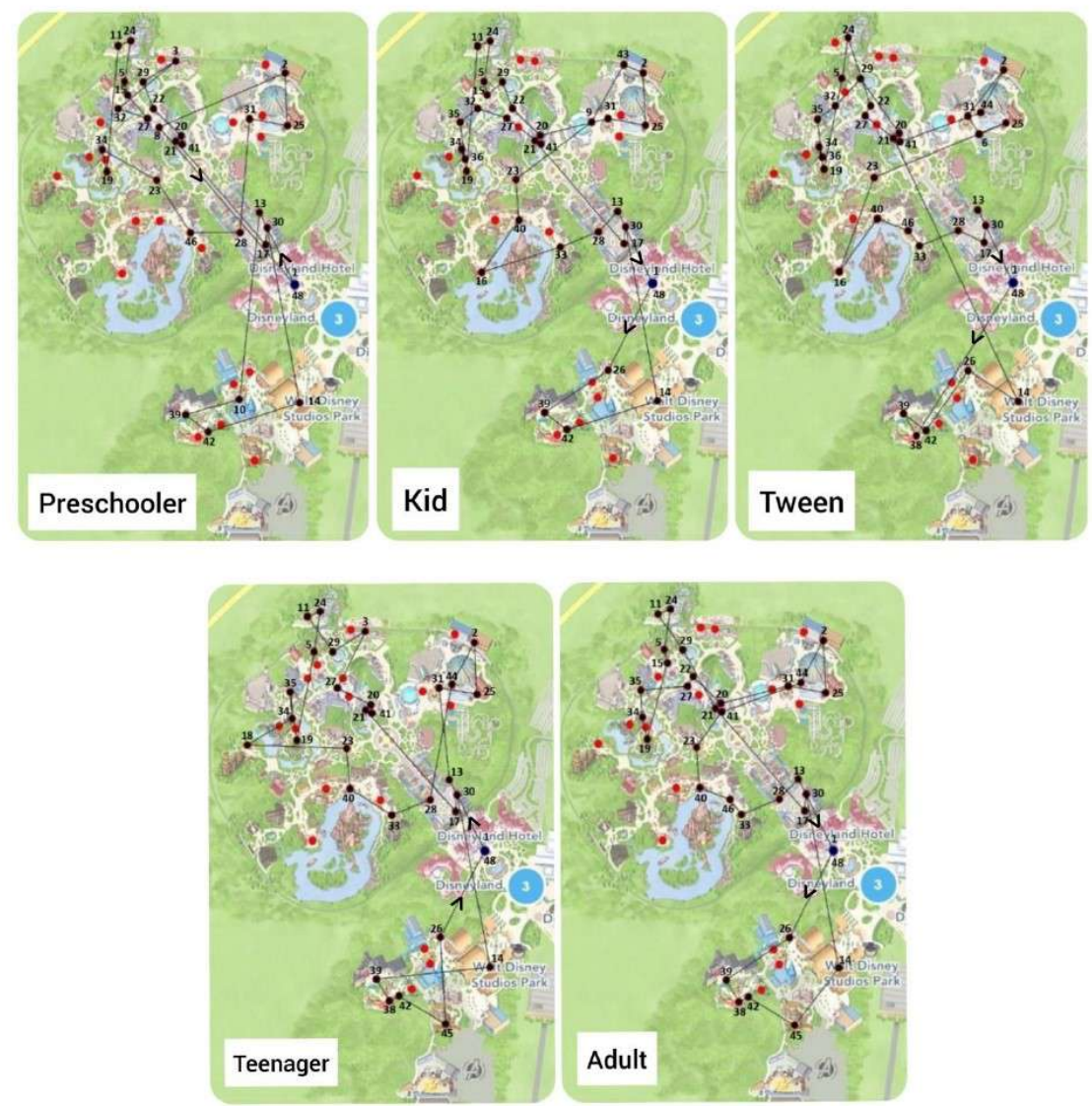

Figure 4. Optimal Paths for each age group. The blue point shows the entrance and exit, the red points show the coordinates of Disneyland's attractions and the black ones indicates the visited attractions for each age group. The black line show the optimal path and the two arrows help the visitor understand from where to start. The optimal values: Preschooler $=111.4, \mathrm{Kid}=128.3$, Tween $=125.6$, Teenager $=109.8$, Adult $=117.9$ Number of games visited: Preschooler $=28, \mathrm{Kid}=32$, Tween $=32$, Teenager $=30$, Adults $=$ 31

not always be the case. Many times, individuals set targets such as "visit $50 \%$ of the attractions" in order to decide how much time they should spend in the park. Table 5 presents the percentage of attractions visited by each age group for different hours, as well as the percentage of the rating achieved by the optimal route compared to the maximum rate an age group can achieve, see Table 2 for the maximum rate. We observe that a Preschooler needs roughly 4 hours to achieve the $50 \%$ goal for both the percentage of attractions visited and rating, a Kid needs roughly 5 hours, and Tweens, Teenagers and Adults need 6 hours to achieve the same goal. Since Preschoolers have less available attractions to visit due to age restrictions, they can visit $90 \%$ of the park in 10 hours. In contrast, Kids, Tweens, Teenagers and Adults can only visit around $70 \%$ of the park within 10 
hours. These results, could be seen as guidelines in deciding how much time one should spend in the park, aiding with the type of ticket one should buy.

It is also interesting to see the overlap in the attractions visited by different age groups. If there are 10 hours available, we observe that all age groups have approximately 20 attractions in common, which make up more that around $70 \%$ of all attractions visited by each group. The overlap in attractions visited leads us to believe that if different age groups move together as a group through the park, they will not experience significant drop in the rating received, something that we will be verified in the following section.

\begin{tabular}{|c|c|c|c|c|c|c|c|c|c|c|}
\hline $\begin{array}{c}\text { Available } \\
\text { Time }\end{array}$ & \multicolumn{2}{|c|}{ Preschoolers } & \multicolumn{2}{|c|}{ Kids } & \multicolumn{2}{|c|}{ Tweens } & \multicolumn{2}{|c|}{ Teenagers } & \multicolumn{2}{|c|}{ Adults } \\
\hline (Minutes) & Attract. & Rate & Attract. & Rate & Attract. & Rate & Attract. & Rate & Attract. & Rate \\
\hline 0 & $0 \%$ & $0 \%$ & $0 \%$ & $0 \%$ & $0 \%$ & $0 \%$ & $0 \%$ & $0 \%$ & $0 \%$ & $0 \%$ \\
\hline 60 & $19 \%$ & $19 \%$ & $16 \%$ & $15 \%$ & $15 \%$ & $14 \%$ & $14 \%$ & $11 \%$ & $14 \%$ & $12 \%$ \\
\hline 120 & $35 \%$ & $35 \%$ & $28 \%$ & $27 \%$ & $26 \%$ & $25 \%$ & $25 \%$ & $23 \%$ & $25 \%$ & $23 \%$ \\
\hline 180 & $45 \%$ & $45 \%$ & $37 \%$ & $36 \%$ & $35 \%$ & $33 \%$ & $32 \%$ & $32 \%$ & $32 \%$ & $32 \%$ \\
\hline 240 & $58 \%$ & $56 \%$ & $44 \%$ & $44 \%$ & $41 \%$ & $41 \%$ & $39 \%$ & $40 \%$ & $41 \%$ & $40 \%$ \\
\hline 300 & $68 \%$ & $65 \%$ & $51 \%$ & $52 \%$ & $48 \%$ & $47 \%$ & $45 \%$ & $47 \%$ & $48 \%$ & $48 \%$ \\
\hline 360 & $71 \%$ & $70 \%$ & $58 \%$ & $58 \%$ & $54 \%$ & $54 \%$ & $52 \%$ & $53 \%$ & $55 \%$ & $54 \%$ \\
\hline 420 & $77 \%$ & $76 \%$ & $63 \%$ & $62 \%$ & $59 \%$ & $58 \%$ & $57 \%$ & $57 \%$ & $59 \%$ & $58 \%$ \\
\hline 480 & $84 \%$ & $82 \%$ & $67 \%$ & $66 \%$ & $63 \%$ & $62 \%$ & $59 \%$ & $62 \%$ & $61 \%$ & $62 \%$ \\
\hline 540 & $87 \%$ & $86 \%$ & $72 \%$ & $71 \%$ & $67 \%$ & $66 \%$ & $64 \%$ & $66 \%$ & $66 \%$ & $66 \%$ \\
\hline 600 & $90 \%$ & $90 \%$ & $74 \%$ & $74 \%$ & $70 \%$ & $69 \%$ & $68 \%$ & $69 \%$ & $70 \%$ & $70 \%$ \\
\hline
\end{tabular}

Table 5. Percentage of attractions visited and percentage of total rating achieved by each group for different available time. Red denotes the maximum time needed to achieve a target of at least $50 \%$, and blue denotes the maximum time needed to achieve a target of at least $70 \%$.

\subsection{Family Trip Experiment}

In this section, we have decided to examine how a family would experience a Disneyland trip. To this end, we consider a family consisting of two adults, two teenagers and a kid. The problem has two phases. In Phase 1 the family members visit the attractions together as a single group and in Phase 2 the group splits with the teenagers playing on their own, while the kid and the adults move together as a single group. If in Phase 1 a particular attraction is visited, then it is removed from the available attractions in Phase 2. Splitting the family into groups for the second part of their trip was motivated by the previous experiment in Section 4.1 which showed that 


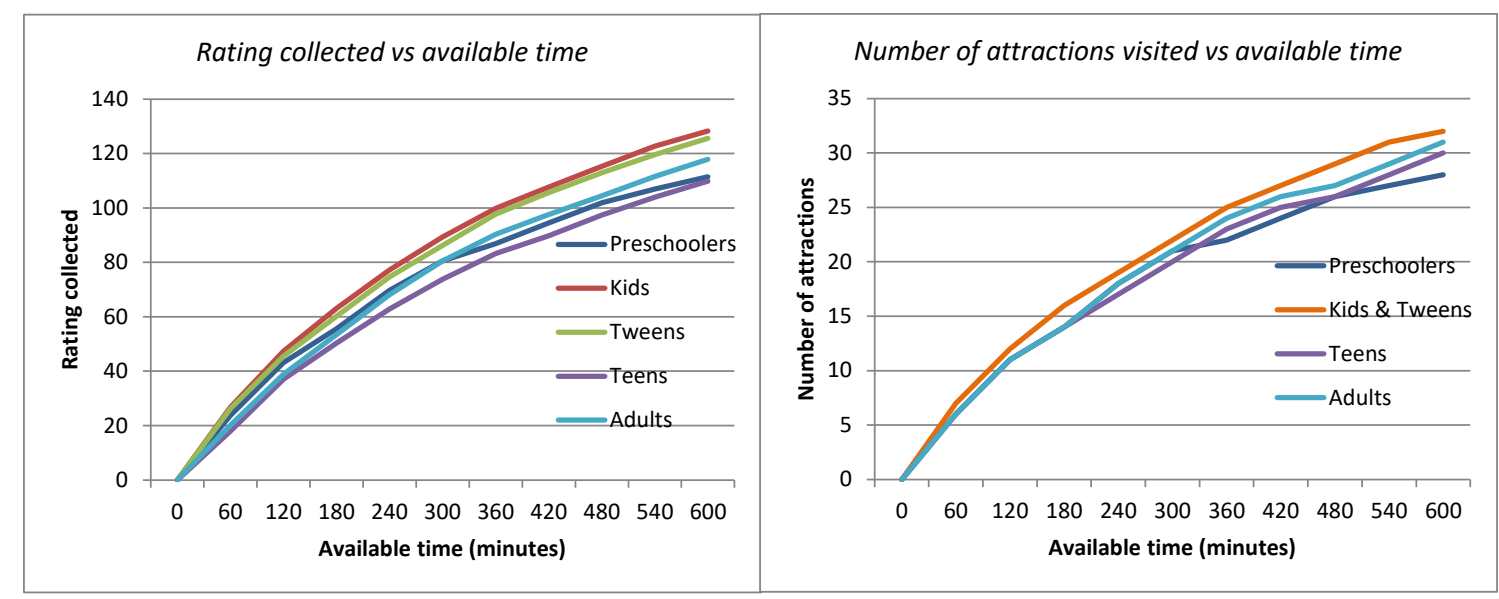

Figure 5. Total rate and total number of visited attractions as functions of available time for each age group

each age group experiences differently its time in Disneyland. The rating used for Phase 1 is the average calculated from every age group that the family consists of. For example, for Mickey's PhilharMagic, the family rating is 4.1 as the ratings for the Kids, Teenagers, Adults are 4.3, 3.9, and 4.1 respectively. In Phase 2 we used two different ratings, as the family splits into two groups. For the teenagers we used their own age group's rate, while for the kid and adults moving together we calculated the average between these two age categories.

In the following we perform two experiments. In Section 4.2.1 we split the available time with a constant ratio 1:1 meaning that if, for example, they have 10 hours available the family visits attractions together for 5 hours and the remaining 5 hours they play separately. We repeat this experiment for $5,6,7,8,9$ and 10 hours. In Section 4.2 .2 we examine the effect of different split times. To this end, we fix the available time to 10 hours and vary the split time to different ratios. Finally, in Section 4.2.3 we investigate how the split time affects families with alternative age group compositions.

In all experiments we solved our optimization problem, as formulated in (3.9), three times for each time ratio. In particular, we first solve the problem for Phase 1 once, when they all play together, and after removing the attractions that the family visited, we resolve the problem two more times for Phase 2, one for the kid with his parents and one for the teenagers. In this way, we prevented the possibility of visiting the same attraction in both rounds. We note that the family will start its trip at the entrance and finish at the exit, and the separate trip for the kid with adults 
and teenagers will also start from the entrance and finish at the exit.

\subsubsection{Constant Time Ratio Experiment}

As described in the Section 4.2, the orienteering problem was solved with a Tmax value equal to $600,540,480,420,360$ and 300 minutes regarding to the constraint (3.6). Specifically, using the constant time ratio 1:1 we have that each phase lasts half of the Tmax. The results are summarized in Figures 6 and 7. We note that the ratings reported in both graphs are calculated as follows: We first solve the two phase routing problems as described at the beginning of Section 4.2. Then, for each age group we calculate the sum of rates collected corresponding to that age group, according to the optimal route of the orienteering problem.

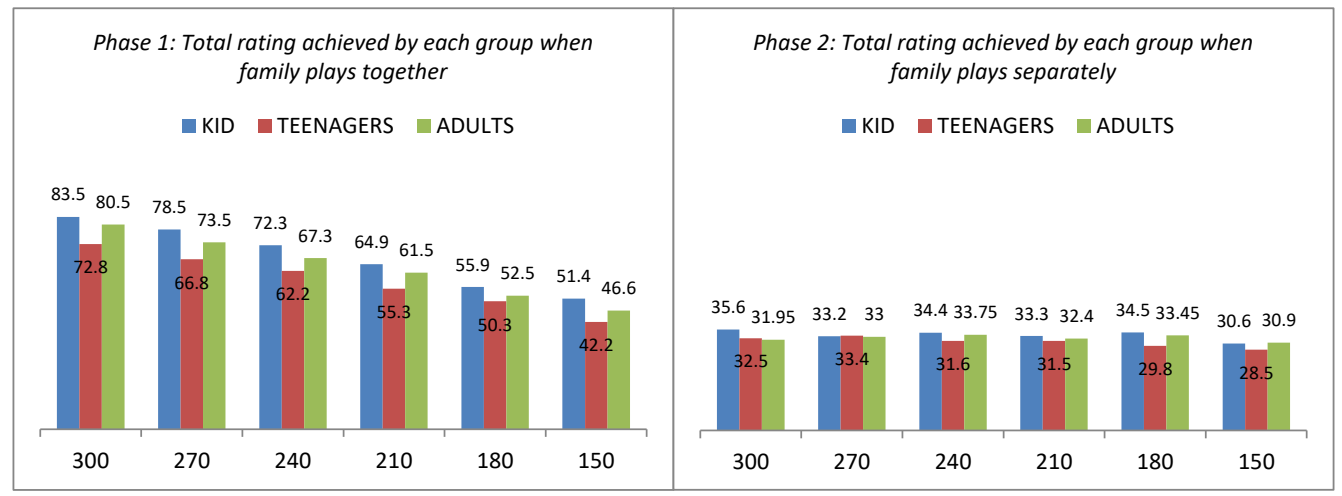

Figure 6. The effects of time on the total rates of each age group. Phase 1 and 2 time ratio is $1: 1$.

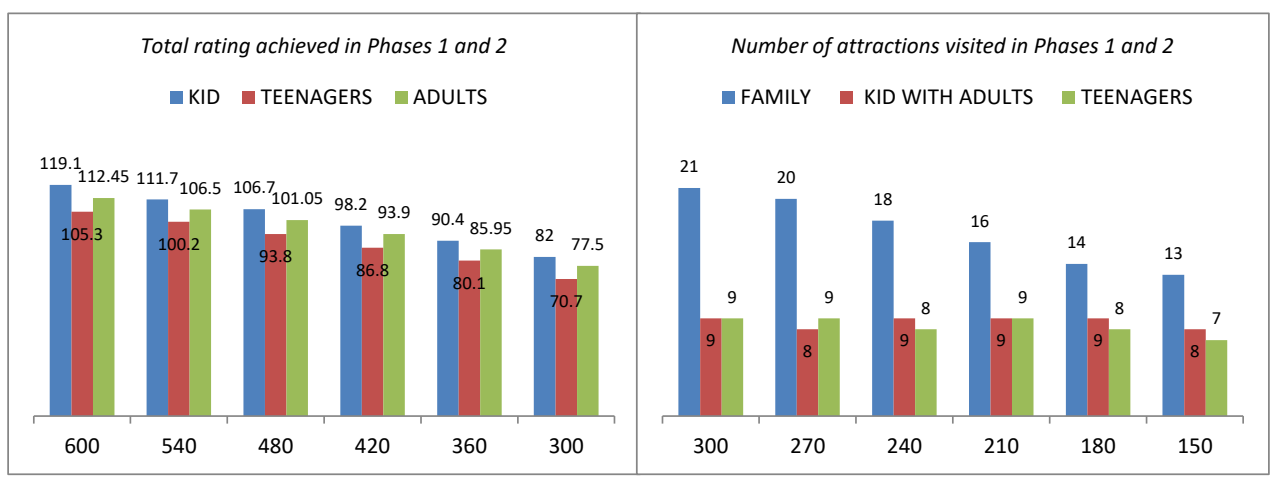

Figure 7. The effects of time on the overall rate and number of attractions visited of each age group.

From Figure 6, we notice that there is a significant difference in the rates collected in the two phases. In Phase 1, Figure 6 (left), as expected we see a decrease in rating as the available time 
decreases in all age groups. However, the results are much less dramatic in Phase 2, Figure 6 (right). In addition, the total rates collected in Phase 2 are significantly lower than the corresponding rates in Phase 1, despite the fact that the time spent in both phases is the same. This can be partly explained by the fact that attractions visited in Phase 1 are excluded from Phase 2, which is compounded by the fact that there is a significant overlap in the attractions visited by all age groups as seen in Section 4.1. The attractions remaining for Phase 2 typically have longer wait plus duration time, and sometimes lower rating, as seen in Table 6 which reports the average rating and average wait time plus duration of attractions in Phases 1 and 2. Figure 7 (left) gives the sum of the ratings from both phases.

\begin{tabular}{|c|c|c|c|c|c|c|c|}
\hline $\begin{array}{c}\text { Available } \\
\text { Time } \\
\text { (Minutes) }\end{array}$ & Average & \multicolumn{3}{|c|}{ Phase 1 } & \multicolumn{3}{c|}{ Phase 2} \\
\hline 600 & Rate/Time) & Kids & Teenagers & Adults & Kids & Teenagers & Adults \\
\hline & Rate & 3.976 & 3.467 & 3.833 & 3.956 & 3.611 & 3.550 \\
& Time & 11.313 & 11.313 & 11.313 & 30.092 & 29.899 & 30.092 \\
\hline 540 & Rate & 3.925 & 3.340 & 3.675 & 4.150 & 3.711 & 4.125 \\
& Time & 10.889 & 10.889 & 10.889 & 30.393 & 26.654 & 30.393 \\
\hline 480 & Rate & 4.017 & 3.456 & 3.739 & 3.822 & 3.950 & 3.750 \\
& Time & 10.453 & 10.453 & 10.453 & 23.849 & 25.702 & 23.849 \\
\hline 420 & Rate & 4.056 & 3.456 & 3.844 & 3.700 & 3.500 & 3.600 \\
& Time & 10.497 & 10.497 & 10.497 & 17.981 & 20.116 & 17.981 \\
\hline 360 & Rate & 3.993 & 3.593 & 3.750 & 3.833 & 3.725 & 3.717 \\
& Time & 9.916 & 9.916 & 9.916 & 14.756 & 18.782 & 14.756 \\
\hline 300 & Rate & 3.954 & 3.246 & 3.585 & 3.825 & 4.071 & 3.863 \\
& Time & 9.653 & 9.653 & 9.653 & 13.389 & 15.511 & 13.389 \\
\hline
\end{tabular}

Table 6. Average rating (Rate) and average wait plus duration time of attractions visited (Time) in Phases 1 and 2 for each age group.

From our observations, we realised that despite the fact that each age group has different rate, the big impact on the rating achieved comes from the family playing together as a single group in Phase 1. This realisation made us conclude that splitting the available time with a time ratio 1:1 for the two phases may not be the best decision as at the end family time turned out to be more effective. In the following section, we examine which time split is more suitable for a family visiting Disneyland. 


\subsubsection{Different Time Ratio Experiment}

We now split the available time for the two phases in different ratios. We aim to understand which will be more suitable for a family: $(i)$ spending all their time as a family, $(i i)$ spending all their time separately, (iii) or balancing between the two. To this end, we split the available 600 minutes (10 hours) as follows: 1:0, 3:2, 11:9, 1:1, 9:11, 2:3, and 0:1. For example, by solving the problem with a ratio of $3: 2$ it is meant the time available in Phase 1 is Tmax $=360$ minutes and in Phase 2 is $\operatorname{Tmax}=240$ minutes. The results are summarized in Figures 8 and 9.

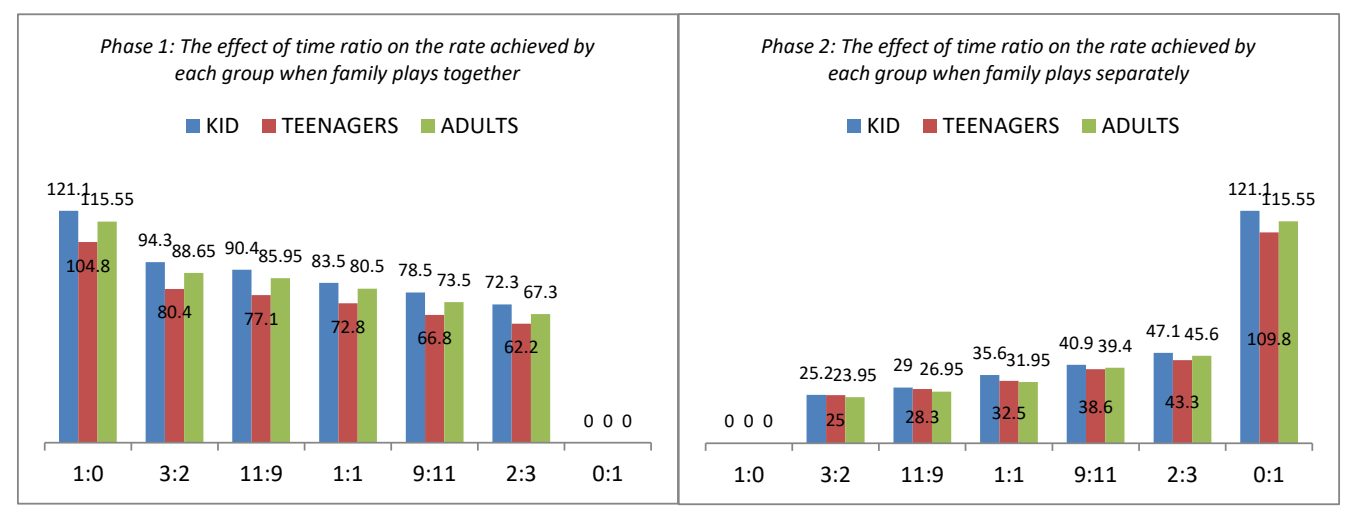

Figure 8. How different time ratios of 600 minutes affect the total number of attractions visited and the total rate collected by each age group.

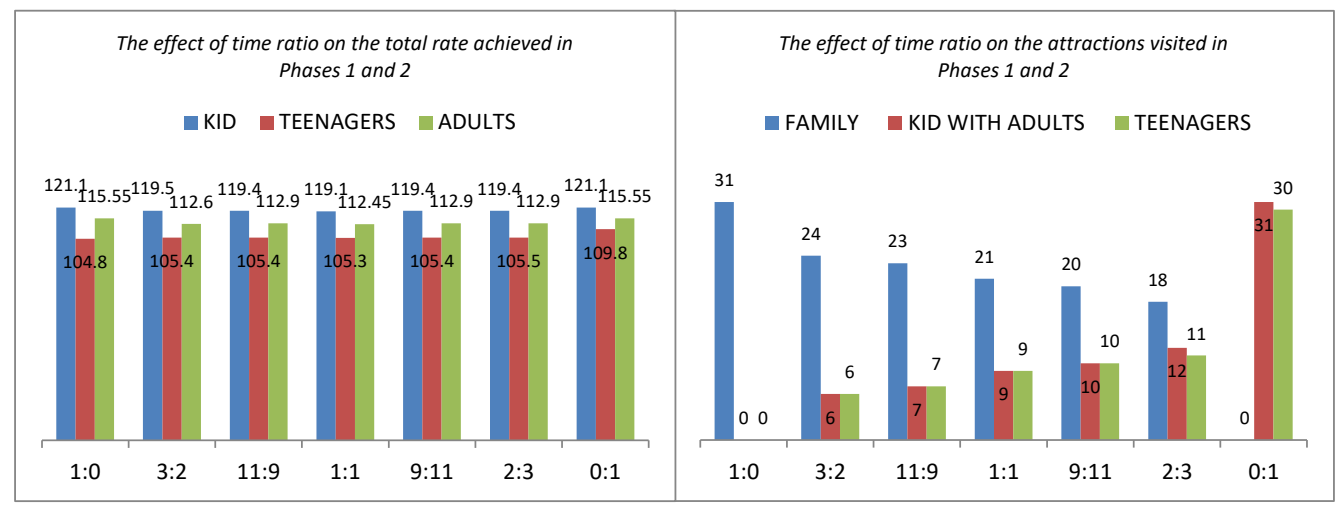

Figure 9. How different time ratios of 600 minutes affect the rate collected playing as a family and the overall rate collected.

Figure 8 depicts the rates collected by each age group in Phase 1 (left) and Phase 2 (right), with 9 (left) depicts the aggregate cumulative rate collected in both periods. Figure 9 (right) records the number of attractions visited in Phase 1 by the family and in Phase 2 by the teenagers, adults and kids. As expected, split 0:1 achieves the best possible rating for teenagers and kids-adults. 
What is interesting, however, is that the difference in total rating achieved is practically the same of all splits with the difference being less than $5 \%$ of the teenagers and less than $2 \%$ of the kids and adults. In addition, we observe that the total number of attractions visited is between 29 and 31 by all age groups. This suggests that all age groups within a family will achieve near optimal routes in terms of rating when navigating the park as a single family group compared to visiting the park individually. This is also true for the number of attractions visited. Hence, a family can manage its time in the park accordingly.

We next try to understand what type of attractions the age groups visit for different time splits.

Figures 11, 12 and 13 of Appendix A, show the attributes of the visited attractions. In general, we don't observe large changes but there are some notable exceptions. For example, the number of "Big Thrills" attractions visited by teenagers increases as the time available in Phase 2 increases. This is also true for the "PhotoPassTM" and "Fastpass" attractions, however, there is only a slight decrease in the number of "Fun for little ones" and "Family Adventure" attractions. For kids and adults, it makes little difference with respect to the time split as they practically visit attractions with similar features and achieve very similar ratings in all time splits. Hence, as there are only few differences, a family might decide to spend more time as a whole instead of being separated, so they can have a family experience.

\subsubsection{Alternative Family Compositions}

The aim of this section is to assess how well our result extends to different family compositions. For this experiment we consider four families comprising of: (i) one preschooler, two teenagers and two adults, (ii) one preschooler, one kid, two teenagers and two adults, (iii) one preschooler, one tween and two adults and (iv) one kid, one tween and two adults. We repeat the experiments from Section 4.2.2 to assess the impact of splitting the available time between the whole family and individual time in the park. Figure 10 reports the total rate achieved in both phases for each age group. The conclusions are similar to the previous section, i.e., the rating achieved by each age group is roughly unchanged across all time allocations. However, for families that include a preschooler, the rating of all age groups is slightly lower when the family spends all its time as a single group (time split 1:0). This is the case as preschoolers have many attractions with age restrictions thus the whole family cannot visit them when they are all together. Yet, when the time 


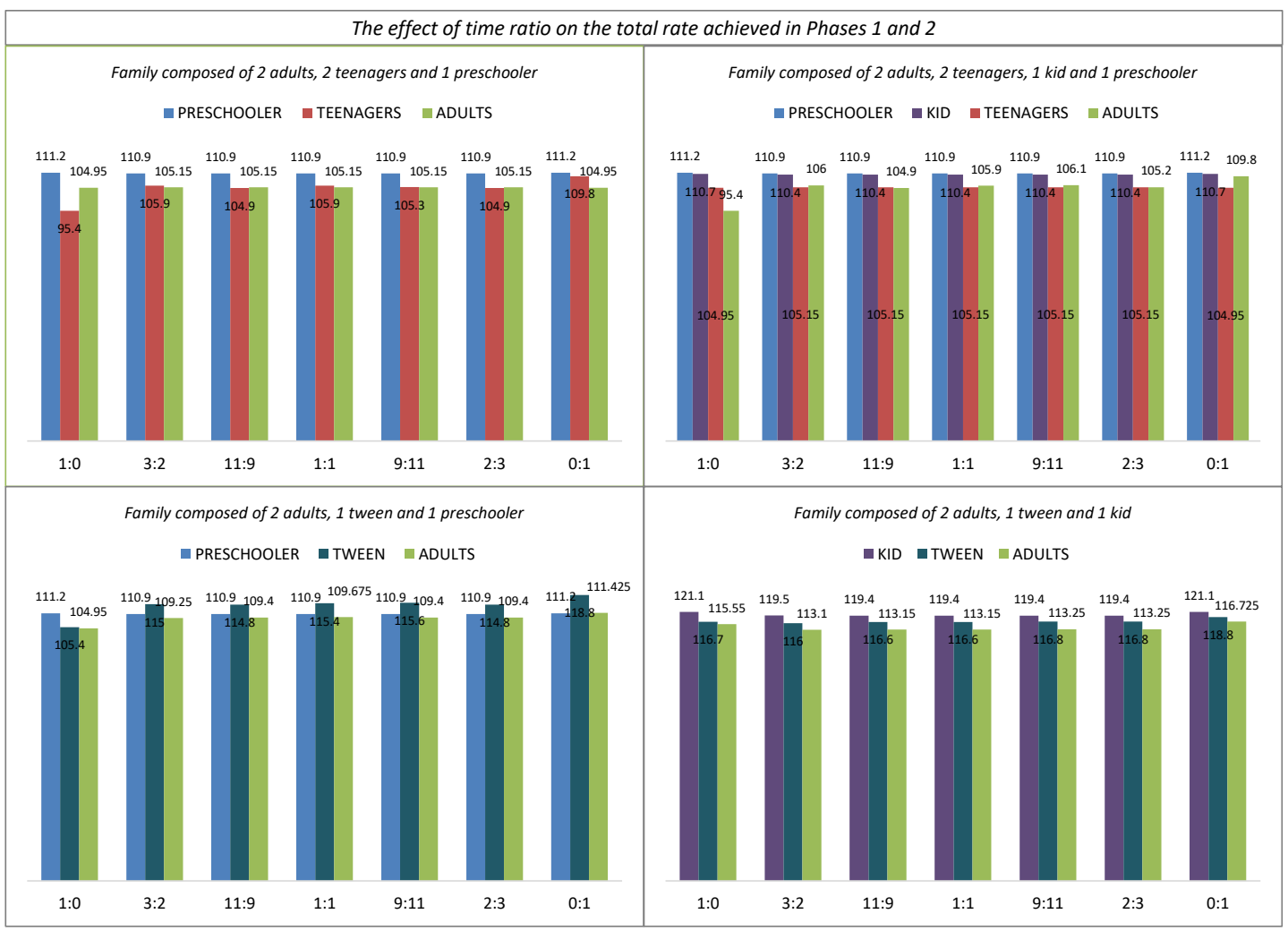

Figure 10. How different time ratios of 600 minutes affect the overall rate collected by each age group of different types of families.

split allocates some time to older members of the family to visit the park on their own, e.g., split $3: 2$, the rating of all age groups increases and remain roughly unchanged across the rest of the time splits. We conclude that families that include the age group of preschoolers, which is restrictive in terms of attractions, might want to allocate some time to older age groups to navigate the park on their own.

\section{Conclusions}

Our study exposes a number of interesting observations. The most striking is that if a family spends all their time together as a single group, the individual age groups in the family will not experience a significant drop in the rate collected compared to navigating the park on their own. This is supported both by the experiments in Section 4.1 in which we observe that there is a significant overlap in the attractions visited between the different age groups, and the experiments in Section 4.2 where we clearly see that splitting the time between family and individual visits does 
not produce significantly difference for all age groups. In addition, the number of available hours in the park will have an effect on the total rating between the age groups, but will not favor one age group over another. Therefore, our recommendation to families is to spend most (or all) their time as a single group as they will achieve practically the same rating as if they would have visited the park independently. This will of course have other side benefits as they will have more fun and memories together.

We will like to emphasize that our analysis heavily depends on the rating of each attraction. In many cases, rating alone might not be the best measure on how each age group experiences each attraction. Families with younger children might prioritize attractions labeled as "Family Adventure" or attractions where the children can meet Disney characters. Although the regression analysis in Section 2 verifies that the ratings are partially influenced by these factors, each family could have different priorities, affecting in different ways the objective function or the orienteering problem. As future work, we would like to examine further the preferences of visitors in Disneyland, and provide a personalized schedule for each visitor. Our long term aim is to create a mobile application in which the user can enter their preferences, and the rating of each attraction will be adjusted accordingly. The application will then recommend the user the optimal route through Disneyland maximizing their experience in the park. 


\section{References}

[1] ABOUT FRANCE.COM. The most visited tourist attraction in france. https://about-france. com/tourism/disneyland-paris.htm. Accessed June 23, 2021.

[2] Balas, E. The prize collecting traveling salesman problem. Networks 19, 6 (1989), 621-636.

[3] Bricker, T. Best disneyland paris attractions and ride guide. https://www . disneytouristblog.com/best-disneyland-paris-attractions-ride-guide/. Accessed June 23, 2021.

[4] Disneyland Paris. Calendar: Validity periods. https://www.disneylandparis.com/ en-int/tickets/1-day-ticket/. Accessed June 23, 2021.

[5] Disneyland Paris. Disneyland paris attractions. https://www.disneylandparis.com/ en-int/attractions/. Accessed June 23, 2021.

[6] Gavalas, D., Konstantopoulos, C., Mastakas, K., and Pantziou, G. A survey on algorithmic approaches for solving tourist trip design problems. Journal of Heuristics 20, 3 (2014), 291-328.

[7] Golden, B. L., Levy, L., And Vohra, R. The orienteering problem. Naval Research Logistics (NRL) 34, 3 (1987), 307-318.

[8] Gunawan, A., Lau, H. C., and Vansteenwegen, P. Orienteering problem: A survey of recent variants, solution approaches and applications. European Journal of Operational Research 255, 2 (2016), 315-332.

[9] Hacking, M. Disneyland paris complete guide and tips (2020). https://www . mousehacking. com/blog/disneyland-paris-trip-planning-guide/. Accessed June 21, 2021.

[10] Howson, I. ols_step_forward_p: Stepwise forward regression. https://rdrr.io/cran/ olsrr/man/ols_step_forward_p.html. Accessed June 23, 2021.

[11] Lazaridou, G. Numerical experiments disneyland paris project. https://github.com/ glazar01/Project-Disneyland-Paris. Accessed June 23, 2021.

[12] LofBerg, J. Yalmip: A toolbox for modeling and optimization in matlab. In 2004 IEEE international conference on robotics and automation (2004), IEEE, pp. 284-289.

[13] Miller, C. E., Tucker, A. W., And Zemlin, R. A. Integer programming formulation of traveling salesman problems. Journal of the ACM (JACM) 7, 4 (1960), 326-329.

[14] Thomadsen, T., And Stidsen, T. K. The quadratic selective travelling salesman problem.

[15] TouringPlans. Disneyland attractions. https://touringplans.com/disneyland/ attractions/. Accessed June 23, 2021.

[16] Tsiligirides, T. Heuristic methods applied to orienteering. Journal of the Operational Research Society 35, 9 (1984), 797-809.

[17] Vansteenwegen, P., Souffriau, W., And Oudheusden, D. V. The orienteering problem: A survey. European Journal of Operational Research 209, 1 (2011), 1-10.

[18] Wang, X., Golden, B. L., And Wasil, E. A. Using a genetic algorithm to solve the generalized orienteering problem. In The vehicle routing problem: latest advances and new challenges. Springer, 2008, pp. 263-274. 


\section{A Appendix}

Table 7. Characteristics for each attraction. With an asterisk we denote attractions for which the age group cannot visit due to age restrictions, however, a rating is still provided in (15).

\begin{tabular}{|c|c|c|c|c|c|c|c|c|}
\hline No & Name & $\begin{array}{c}\text { Duration } \\
(\mathrm{m})\end{array}$ & $\begin{array}{c}\text { Wait } \\
\text { time }(\mathrm{m})\end{array}$ & $\begin{array}{c}\text { Rate } \\
\text { Preschooler }\end{array}$ & $\begin{array}{c}\text { Rate } \\
\text { Kid }\end{array}$ & $\begin{array}{c}\text { Rate } \\
\text { Tween }\end{array}$ & $\begin{array}{l}\text { Rate } \\
\text { Teen }\end{array}$ & $\begin{array}{l}\text { Rate } \\
\text { Adult }\end{array}$ \\
\hline 2 & Mickey's PhilharMagic & 12 & 0 & 4.1 & 4.3 & 4.3 & 3.9 & 4.1 \\
\hline$\overline{3}$ & It's a small world & 12 & 26.11 & 4.6 & 3.9 & 3.4 & 3.7 & 4.15 \\
\hline 4 & Adventure Isle & 60 & 0 & 4 & 4 & 4 & 3.5 & 3.5 \\
\hline 5 & Alice's Curious Labyrinth & 4 & 5.39 & 4.3 & 4 & 3.3 & 3.6 & 3.7 \\
\hline 6 & Autopia & 5.75 & 32.325 & $4.1^{*}$ & 4.3 & 3.7 & 3 & 3.1 \\
\hline 7 & Big Thunder Mountain & 4.25 & 50.995 & $3.5^{*}$ & 4.7 & 4.8 & 4.8 & 4.55 \\
\hline 8 & Blanche-Neige et les Sept Nains & 3 & 52.21 & 4 & 4.4 & 4.4 & 4.4 & 4.4 \\
\hline 9 & Buzz Lightyear Blast & 4.75 & 37.55 & $4.3^{*}$ & 4.4 & 4.2 & 4 & 4.15 \\
\hline 10 & Cars Quatre Roues Rallye & 2 & 56.01 & 4.3 & 4.3 & 4.3 & 3.7 & 3.8 \\
\hline 11 & Cassey Jr.- le Petit Train du Cirque & 3.5 & 18.805 & 4.3 & 3.5 & 2.7 & 2.9 & 3.25 \\
\hline 12 & Crush's Coaster & 3 & 71.66 & $1.6^{*}$ & 4.5 & 4.5 & 4.9 & 4.7 \\
\hline 13 & Discovery Arcade & 9.8 & 0 & 3.3 & 4 & 4 & 3.8 & 3.3 \\
\hline 14 & Disney Studio 1 & 9.5 & 0 & 2.8 & 3.7 & 3.7 & 4.1 & 4.5 \\
\hline 15 & Dumbo the Flying Elephant & 2.335 & 31.895 & 4.6 & 4.1 & 3.4 & 3.6 & 3.7 \\
\hline 16 & Frontierland Playground & 5 & 0 & $4.3^{*}$ & 4.6 & 4.6 & $3.9^{*}$ & $3.7^{*}$ \\
\hline 17 & Horse-Drawn Streetcars & 7 & 9.67 & 4.1 & 4.3 & 3.6 & 4.2 & 4.45 \\
\hline 18 & Indiana Jones:Temple of Peril & 3 & 41.815 & $1.6^{*}$ & $4.1^{*}$ & 4.7 & 4.8 & 4.4 \\
\hline 19 & La Cabane des Robinson & 5 & 1.95 & 4 & 4 & 4 & 2 & 3.25 \\
\hline 20 & La Galerie de la Belle au Bois Dormant & 15 & 0.56 & 3 & 2.7 & 2.7 & 3.6 & 4.2 \\
\hline 21 & La Taniere du Dragon & 6 & 0 & 3 & 3 & 3 & 2.5 & 3 \\
\hline 22 & Le Carrousel de Lancelot & 5 & 9.06 & 3.5 & 3.5 & 3.5 & 1 & 2 \\
\hline 23 & Le Passage Enchante d'Aladdin & 10 & 0 & 4.7 & 4.4 & 4.4 & 3.7 & 4 \\
\hline 24 & Le Pays des Contes de Fees & 3 & 7.1 & 4 & 4 & 4 & 1 & 4 \\
\hline 25 & Les Mysteres du Nautilus & 10 & 4.83 & 3.5 & 3.5 & 3.5 & 3 & 4 \\
\hline 26 & Les Tapis Volants & 2 & 11.93 & $4.5^{*}$ & 4.1 & 4.1 & 3.2 & 3.4 \\
\hline 27 & Les Voyages de Pinocchio & $\overline{3}$ & 16.997 & 3.6 & 3.4 & 3.2 & $3 . \overline{3}$ & 3.45 \\
\hline 28 & Liberty Arcade & 8.98 & 1.02 & 3.3 & 4 & 4 & 3.8 & 3.3 \\
\hline 29 & Mad Hatter's Tea Cups & 3 & 9.06 & 4.4 & 4.3 & 4 & 4.1 & 3.7 \\
\hline 30 & Main Street Vehicles & 4 & 8.22 & 4.1 & 4.3 & 3.6 & 4.2 & 4.45 \\
\hline 31 & Orbitron & 3 & 22.18 & 4.3 & 3.9 & 3.4 & 3.3 & 2.7 \\
\hline 32 & Peter Pan's Flight & 3 & 42.19 & 5 & 5 & 5 & 3 & 4 \\
\hline 33 & Phantom Manor & 7 & 12.03 & $5^{*}$ & 5 & 5 & 4 & 5 \\
\hline 34 & Pirate Galleon & 3 & 0 & 4 & 3.5 & 3.5 & 2.4 & 2.4 \\
\hline 35 & Pirates of the Caribbean & 10 & 25.845 & 3.8 & 4.3 & 4.6 & 4.7 & 4.7 \\
\hline 36 & Pirates' Beach & 3 & 0 & $3.7^{*}$ & 3.6 & 3.6 & $3^{*}$ & $3.3^{*}$ \\
\hline 37 & Princess Pavilion & 14.5 & 64.33 & 4.4 & 4.1 & 4.1 & 3 & 3.2 \\
\hline 38 & RC Racer & 2 & 35.6 & $1.9^{*}$ & 3.6 & 4.5 & 4.7 & 4.5 \\
\hline 39 & Ratatouille: The Adventure & 5 & 9.27 & 4.4 & 4.1 & 4.1 & 3 & 3.2 \\
\hline 40 & Rustler Roundup Shootin' Gallery & 9 & 4.3 & $4.8^{*}$ & 4 & 4 & 3.8 & 3.3 \\
\hline 41 & Sleeping Beauty Castle & 6 & 0 & 3.8 & 3.6 & 3.1 & 3.1 & 3.75 \\
\hline 42 & Slinky Dog Zigzag Spin & 2 & 10.96 & 4.3 & 4.8 & 4.8 & 4.6 & 4.7 \\
\hline 43 & StarTours:The Adventures Continue & 7 & 39.935 & $3.7^{*}$ & 4.5 & 4.4 & 4.5 & 4.4 \\
\hline 44 & Star Wars Hyperspace Mountain & 3 & 27.36 & $2.6^{*}$ & $4.4^{*}$ & 4.9 & 4.9 & 4.4 \\
\hline 45 & The Twilight Zone Tower of Terror & 5 & 37.84 & $2.8^{*}$ & $4^{*}$ & 4 & 4.7 & 4.7 \\
\hline 46 & Thunder Mesa Riverboat Landing & 15 & 20.91 & 4 & 4 & 4 & 2 & 4 \\
\hline 47 & Toy Soldiers Parachute Drop & 2 & 32.08 & $3.6^{*}$ & 3.4 & 3.4 & 2.8 & 2.6 \\
\hline
\end{tabular}


Table 8. Services for each attraction

\begin{tabular}{|c|c|c|}
\hline Services & No of attractions & Total of attractions \\
\hline Single Rider & $12,38,39,44,47$ & 5 \\
\hline Fastpass & $7,9,18,32,39,43,44,45$ & 8 \\
\hline PhotoPass TM & $7,35,44,45$ & 4 \\
\hline Meet Disney Characters & 37 & 1 \\
\hline
\end{tabular}



Figure 11. Visited attractions compared to available attractions for time ratio 1:0 for family experiment in Section 4.2.2 
Table 9. Features of each attraction

\begin{tabular}{|c|c|c|c|c|c|c|}
\hline No & $\begin{array}{c}\text { Family } \\
\text { Adventure }\end{array}$ & $\begin{array}{l}\text { Fun for } \\
\text { little Ones }\end{array}$ & $\begin{array}{c}\text { Guest May } \\
\text { Get Splashed }\end{array}$ & $\begin{array}{c}\text { Not to } \\
\text { be Missed }\end{array}$ & $\begin{array}{c}\text { Big } \\
\text { Thrills }\end{array}$ & $\begin{array}{c}\text { May Frighten } \\
\text { Younger Guests }\end{array}$ \\
\hline 2 & $\checkmark$ & $\checkmark$ & $\checkmark$ & $\sqrt{ }$ & $x$ & $x$ \\
\hline 3 & $x$ & $\checkmark$ & $x$ & $x$ & $x$ & $x$ \\
\hline 4 & $\checkmark$ & $x$ & $x$ & $x$ & $x$ & $x$ \\
\hline 5 & $x$ & $\checkmark$ & $x$ & $x$ & $x$ & $x$ \\
\hline 6 & $x$ & $\checkmark$ & $x$ & $x$ & $x$ & $x$ \\
\hline 7 & $x$ & $x$ & $x$ & $\checkmark$ & $\checkmark$ & $x$ \\
\hline 8 & $\checkmark$ & $x$ & $x$ & $x$ & $x$ & $\checkmark$ \\
\hline 9 & $\checkmark$ & $x$ & $x$ & $\checkmark$ & $x$ & $x$ \\
\hline 10 & $x$ & $\checkmark$ & $x$ & $\checkmark$ & $x$ & $x$ \\
\hline 11 & $x$ & $\checkmark$ & $x$ & $\checkmark$ & $x$ & $x$ \\
\hline 12 & $x$ & $x$ & $x$ & $\checkmark$ & $\checkmark$ & $x$ \\
\hline 13 & $x$ & $x$ & $x$ & $x$ & $x$ & $x$ \\
\hline 14 & $\checkmark$ & $x$ & $x$ & $x$ & $x$ & $x$ \\
\hline 15 & $x$ & $\checkmark$ & $x$ & $x$ & $x$ & $x$ \\
\hline 16 & $x$ & $\checkmark$ & $x$ & $x$ & $x$ & $x$ \\
\hline 17 & $x$ & $\checkmark$ & $x$ & $\checkmark$ & $x$ & $x$ \\
\hline 18 & $x$ & $x$ & $x$ & $\checkmark$ & $\checkmark$ & $x$ \\
\hline 19 & $\checkmark$ & $x$ & $x$ & $x$ & $x$ & $x$ \\
\hline 20 & $\checkmark$ & $x$ & $x$ & $x$ & $x$ & $x$ \\
\hline 21 & $x$ & $x$ & $x$ & $x$ & $x$ & $\checkmark$ \\
\hline 22 & $x$ & $\checkmark$ & $x$ & $x$ & $x$ & $x$ \\
\hline 23 & $x$ & $\checkmark$ & $x$ & $x$ & $x$ & $x$ \\
\hline 24 & $x$ & $\checkmark$ & $x$ & $\checkmark$ & $x$ & $x$ \\
\hline 25 & $\checkmark$ & $x$ & $x$ & $\checkmark$ & $x$ & $x$ \\
\hline 26 & $x$ & $\checkmark$ & $x$ & $x$ & $x$ & $x$ \\
\hline 27 & $\checkmark$ & $x$ & $x$ & $x$ & $x$ & $\checkmark$ \\
\hline 28 & $x$ & $x$ & $x$ & $x$ & $x$ & $x$ \\
\hline 29 & $\checkmark$ & $x$ & $x$ & $\checkmark$ & $x$ & $x$ \\
\hline 30 & $x$ & $\checkmark$ & $x$ & $x$ & $x$ & $x$ \\
\hline 31 & $\checkmark$ & $\checkmark$ & $x$ & $x$ & $x$ & $x$ \\
\hline 32 & $x$ & $x$ & $x$ & $\checkmark$ & $x$ & $x$ \\
\hline 33 & $\checkmark$ & $x$ & $x$ & $\checkmark$ & $x$ & $\checkmark$ \\
\hline 34 & $\checkmark$ & $x$ & $x$ & $x$ & $x$ & $x$ \\
\hline 35 & $\checkmark$ & $x$ & $\checkmark$ & $\checkmark$ & $x$ & $\checkmark$ \\
\hline 36 & $x$ & $\checkmark$ & $x$ & $x$ & $x$ & $x$ \\
\hline 37 & $x$ & $\checkmark$ & $x$ & $x$ & $x$ & $x$ \\
\hline 38 & $x$ & $x$ & $x$ & $\checkmark$ & $\checkmark$ & $x$ \\
\hline 39 & $x$ & $\checkmark$ & $\checkmark$ & $x$ & $x$ & $\checkmark$ \\
\hline 40 & $\checkmark$ & $x$ & $x$ & $x$ & $x$ & $x$ \\
\hline 41 & $\checkmark$ & $x$ & $x$ & $x$ & $x$ & $x$ \\
\hline 42 & $x$ & $\checkmark$ & $x$ & $\checkmark$ & $x$ & $x$ \\
\hline 43 & $x$ & $x$ & $x$ & $x$ & $\checkmark$ & $x$ \\
\hline 44 & $x$ & $x$ & $x$ & $\checkmark$ & $\checkmark$ & $x$ \\
\hline 45 & $x$ & $x$ & $x$ & $\checkmark$ & $\checkmark$ & $x$ \\
\hline 46 & $\checkmark$ & $x$ & $x$ & $\checkmark$ & $x$ & $x$ \\
\hline 47 & $\checkmark$ & $x$ & $x$ & $\checkmark$ & $x$ & $x$ \\
\hline Total & 18 & 19 & 3 & 20 & 7 & 6 \\
\hline
\end{tabular}


Table 10. Restrictions for each attraction

\begin{tabular}{|c|c|c|c|c|c|}
\hline No & Preschoolers & Kids & Tweens & $\begin{array}{c}\text { Teenagers } \\
\text { Adults }\end{array}$ & Height Limit(m) \\
\hline $\begin{array}{l}2 \\
3\end{array}$ & $\checkmark$ & $\sqrt{1}$ & $\sqrt{1}$ & 5 & - \\
\hline $\begin{array}{l}3 \\
4\end{array}$ & $\checkmark$ & $\checkmark$ & $\checkmark$ & $\checkmark$ & - \\
\hline $\begin{array}{l}4 \\
5\end{array}$ & 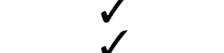 & $\checkmark$ & 3 & 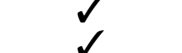 & - \\
\hline 6 & $x$ & $\checkmark$ & $\checkmark$ & $\checkmark$ & 0.81 \\
\hline 7 & $x$ & $\checkmark$ & $\checkmark$ & $\checkmark$ & 1.02 \\
\hline 8 & $\checkmark$ & $\checkmark$ & $\checkmark$ & $\checkmark$ & - \\
\hline 9 & $x$ & $\checkmark$ & $\checkmark$ & $\checkmark$ & - \\
\hline 10 & $\checkmark$ & $\checkmark$ & $\checkmark$ & $\checkmark$ & - \\
\hline 11 & $\checkmark$ & $\checkmark$ & $\checkmark$ & $\checkmark$ & - \\
\hline 12 & $x$ & $\checkmark$ & $\checkmark$ & $\checkmark$ & 1.07 \\
\hline 13 & $\checkmark$ & $\checkmark$ & $\checkmark$ & $\checkmark$ & - \\
\hline 14 & $\checkmark$ & $\checkmark$ & $\checkmark$ & $\checkmark$ & - \\
\hline 15 & $\checkmark$ & $\checkmark$ & $\checkmark$ & $\checkmark$ & - \\
\hline 16 & $x$ & $\checkmark$ & $\checkmark$ & $x$ & - \\
\hline 17 & $\checkmark$ & $\checkmark$ & $\checkmark$ & $\checkmark$ & - \\
\hline 18 & $x$ & $x$ & $\checkmark$ & $\checkmark$ & 1.4 \\
\hline 19 & $\checkmark$ & $\checkmark$ & $\checkmark$ & $\checkmark$ & - \\
\hline 20 & $\checkmark$ & $\checkmark$ & $\checkmark$ & $\checkmark$ & - \\
\hline 21 & $\checkmark$ & $\checkmark$ & $\checkmark$ & $\checkmark$ & - \\
\hline $\begin{array}{l}22 \\
23\end{array}$ & $\checkmark$ & $\checkmark$ & $\checkmark$ & $\checkmark$ & - \\
\hline $\begin{array}{l}23 \\
24\end{array}$ & $\checkmark$ & $\sqrt{2}$ & 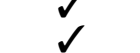 & $\sqrt{2}$ & - \\
\hline 25 & $\checkmark$ & $\checkmark$ & $\checkmark$ & $\checkmark$ & - \\
\hline 26 & $x$ & $\checkmark$ & $\checkmark$ & $\checkmark$ & - \\
\hline 27 & $\checkmark$ & $\checkmark$ & $\checkmark$ & $\checkmark$ & - \\
\hline 28 & $\checkmark$ & $\checkmark$ & $\checkmark$ & $\checkmark$ & - \\
\hline 29 & $\checkmark$ & $\checkmark$ & $\checkmark$ & $\checkmark$ & - \\
\hline 30 & $\checkmark$ & $\checkmark$ & $\checkmark$ & $\checkmark$ & - \\
\hline 31 & $\checkmark$ & $\checkmark$ & $\checkmark$ & $\checkmark$ & - \\
\hline 32 & $\checkmark$ & $\checkmark$ & $\checkmark$ & $\checkmark$ & - \\
\hline 33 & $x$ & $\checkmark$ & $\checkmark$ & $\checkmark$ & - \\
\hline 34 & $\checkmark$ & $\checkmark$ & $\checkmark$ & $\checkmark$ & - \\
\hline 35 & $\checkmark$ & $\checkmark$ & $\checkmark$ & 1 & - \\
\hline 36 & $x$ & $\checkmark$ & $\checkmark$ & $x$ & - \\
\hline 37 & $\sqrt{x}$ & $\checkmark$ & $\checkmark$ & $\checkmark$ & - \\
\hline 38 & $x$ & $\checkmark$ & $\checkmark$ & $\checkmark$ & 1.2 \\
\hline 39 & $\checkmark$ & $\checkmark$ & $\checkmark$ & $\checkmark$ & - \\
\hline 40 & $x$ & $\checkmark$ & $\checkmark$ & $\checkmark$ & - \\
\hline 41 & $\checkmark$ & $\checkmark$ & $\checkmark$ & $\checkmark$ & - \\
\hline 42 & $\checkmark$ & $\checkmark$ & $\checkmark$ & $\checkmark$ & - \\
\hline 43 & $x$ & $\checkmark$ & $\checkmark$ & $\checkmark$ & 1.02 \\
\hline 44 & $x$ & $x$ & $\checkmark$ & $\checkmark$ & 1.2 \\
\hline 45 & $x$ & $x$ & $\checkmark$ & $\checkmark$ & 1.02 \\
\hline 46 & $\checkmark$ & $\checkmark$ & $\checkmark$ & $\checkmark$ & - \\
\hline 47 & $x$ & $v$ & $v$ & $v$ & 0.81 \\
\hline $\begin{array}{c}\text { Total Available } \\
\text { Attractions }\end{array}$ & 31 & 43 & 46 & 44 & 37 \\
\hline $\begin{array}{c}\text { Total Restricted } \\
\text { Attractions }\end{array}$ & 15 & 3 & 0 & 2 & 9 \\
\hline
\end{tabular}






Figure 12. Visited attractions compared to available attractions for time ratios $3: 2$, 11:9 and 1:1 for family experiment in Section 4.2.2 


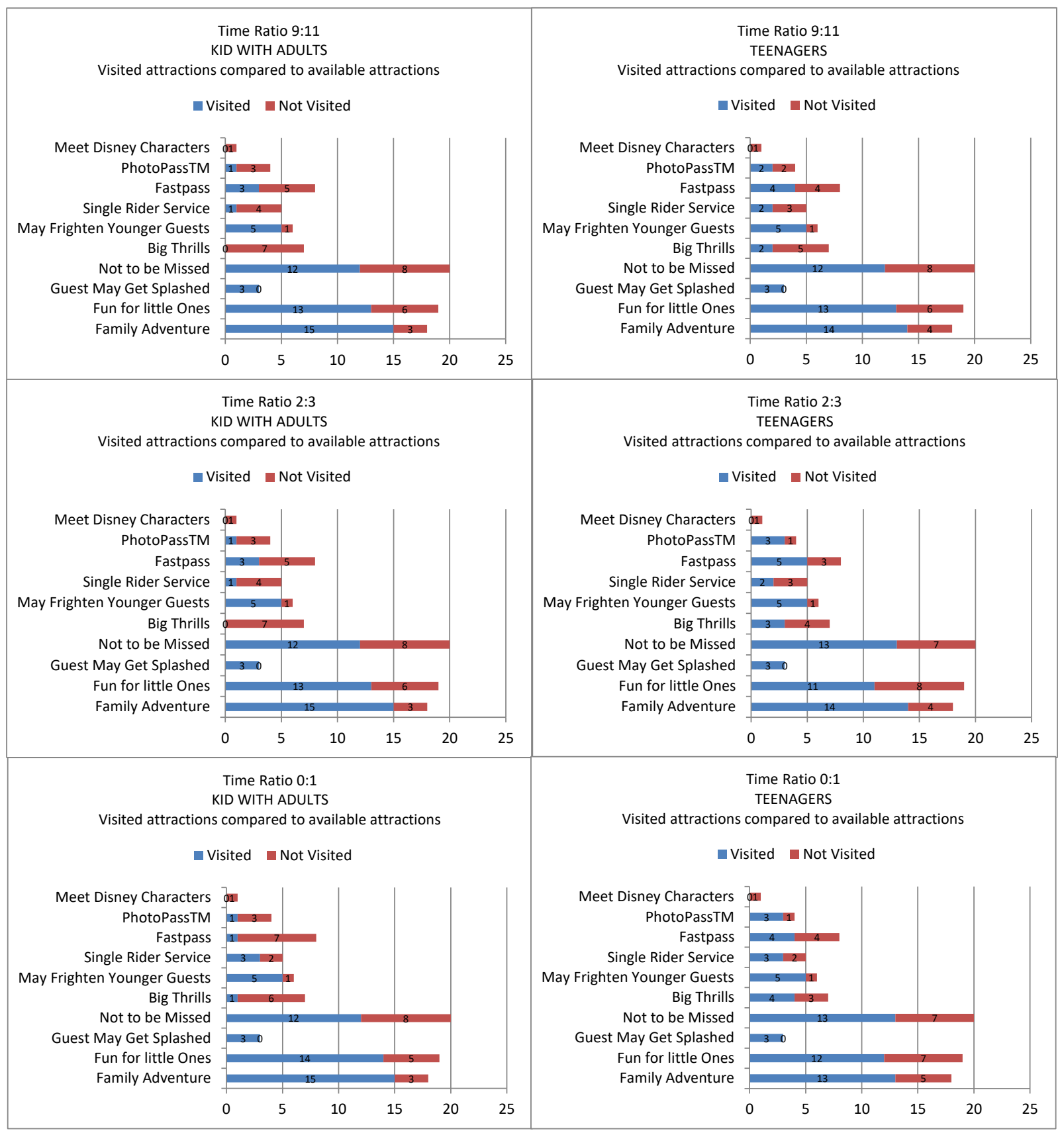

Figure 13. Visited attractions compared to available attractions for time ratios 9:11, 2:3 and 0:1 for family experiment in Section 4.2 .2 


\section{Acknowledgement}

We would like to express our special thanks of gratitude to our advisor Professor Dr. Angelos Georghiou for the patient guidance, encouragement and advice he has provided throughout our time as his students. We consider ourselves to be extremely privileged to have been his students because we benefited enormously from his excellence as a teacher and as a researcher. In particular, he has encouraged our research and has made a significant contribution to our completion of this study, without him we could not have completed this project. These contributors have enhanced the quality of our work. We have been extremely lucky to have a supervisor who cared so much about our work. 